\section{Biliary Peritonitis in Pregnancy}

Brit. med. F., 1965, 2, 744

A search of the literature reveals no case of biliary peritonitis due to perforation of the gall-bladder in the middle trimester of pregnancy.

\section{CASE RePort}

A married woman presented complaining of severe abdominal pain. One month before admission she had had an attack of severe colicky pain in the right hypochondrium which settled within six hours. Twenty-four hours before she was admitted she developed the same pain associated with vomiting. This persisted for 12 hours and then settled. Six hours before admission she developed persistent pain all over the abdomen, but most severe in the right hypochondrium and right lliac fossa. Large quantities of darkbrown fluid had been vomited two hours before admission. Her last menstrual period was on 10 February 1964, and she was 23 weeks pregnant. In 1963 she had been admitted to hospital with "gall-stones" for observation.

On examination she was not shocked but was moderately dehydrated. Her temperature was $98.2^{\circ} \mathrm{F}$. $\left(36.8^{\circ} \mathrm{C}\right.$.), blood-pressure $140 / 80 \mathrm{~mm}$. Hg. Examination of the cardiovascular and respiratory systems revealed no abnormality apart from a tachycardia of 128 beats per minute. Abdominal examination revealed some distension with guarding over the whole abdomen, most marked in the right hypochondrium. The fundus of the uterus corresponded with 24 weeks' gestation. No other masses were palpable. There was severe tenderness in the right hypochondrium. Marked rebound tenderness was present. No free fluid was detected, and bowel sounds were present but diminished in quantity.

Urinalysis revealed the presence of acetone and albumin only. Haemoglobin was $99 \%$, white-cell count $28,400,89 \%$ neutrophils.

A diagnosis of peritonitis due to perforation of the gall-bladder was made. A surgical opinion confirmed this diagnosis. Continuous gastric suction via a Ryle tube and an intravenous infusion of normal saline were started. Laparotomy was performed through an upper right paramedian incision. Six ounces $(170 \mathrm{ml}$.) of bilestained fluid lying free in the peritoneal cavity was found. The gall-bladder contained a stone in the region of Hartmann's pouch and two smaller stones at the fundus. There was a small perforation between these two stones, through which bile was draining. An easy cholecystectomy was performed.

The post-operative regimen consisted of gastric suction and intravenous fluids controlled by daily estimation of electrolytes. Tetracycline, $250 \mathrm{mg}$., was added to each $500 \mathrm{ml}$. of fluid. Diamorphine, $10 \mathrm{mg}$. six-hourly for 48 hours, and Parentrovite were also given.

Foetal movements were felt for the first time on the third postoperative day. Haemoglobin was $76 \%$, white-cell count 10,400 , serum bilirubin $1.2 \mathrm{mg} . / 100 \mathrm{ml}$., and serum electrolytes normal. The patient was discharged on the fourteenth post-operative day. The serum bilirubin was then $0.8 \mathrm{mg} . / 100 \mathrm{ml}$.

The pathology report showed acute cholecystitis with perforation at the fundus. A further ulcerated area with a fragment of stone at its base which had almost perforated was also noted.

At the 39th week of pregnancy the blood-pressure was found to be $140 / 100 \mathrm{~mm} . \mathrm{Hg}$, and there was some oedema of the lower limbs. Blood-pressure increased to $160 / 110 \mathrm{~mm}$. $\mathrm{Hg}$ and albuminuria appeared in spite of bed rest and sedation. Labour was induced surgically and delivery effected by low forceps extraction of a living male infant. The puerperium was uneventful.

\section{COMMENT}

There is still a difference of opinion concerning the frequency with which the gall-bladder perforates. Perforation into the peritoneal cavity is uncommon (Bailey and Love, 1959), occur- ring in only $0.5 \%$ of cases being conservatively treated for acute cholecystitis. Chronic cholecystitis usually remains quiescent throughout pregnancy, with the occurrence of exacerbations in the puerperium (Reid, 1962). Morse et al. (1957) found that of 25 cases of acute perforation of the gall-bladder in 542 patients (incidence $4.6 \%$ ) $40 \%$ had free perforation into the peritoneal cavity, with a mortality of $60 \%$. In this series where no surgical treatment was undertaken the mortality was $100 \%$. Becker (1957) also found that in his cases of acute cholecystitis treated surgically the mortality rate was increased threefold if perforation had occurred. Fletcher and Ravdin (1951) found that perforation into the peritoneal cavity occurred in $29 \%$ of their series. These workers attributed the reduced incidence of perforation to surgical intervention in the early stages of the disease.

Berk (1940) found an incidence of perforation of $2.5 \%$ of his series of patients with acute cholecystitis, while Hallendorf et al. (1948) found no perforation in 100 patients with gangrene of the gall-bladder.

It is surprising that this condition does not occur more of ten in pregnancy because of the increased cholesterol content of the bile and the biliary stasis noted during pregnancy. This is probably attributable to the fact that gall-stones are more frequently found in the older age groups of women nearing the end of their child-bearing years (Becker, 1957).

In this case the diagnosis was made pre-operatively because of the history of gall-bladder disease and of the presenting symptoms and signs. Successful treatment was due to prompt surgical intervention and to the fact that cholecystectomy was facilitated by the absence of peritonitis with adhesions in the region of the gall-bladder. Many workers do not recommend this mode of treatment, advocating instead drainage of the gallbladder in the first instance and its removal at a later date. We think that in this patient early diagnosis and prompt radical surgery resulted in the successful continuation of pregnancy to term with reduction of maternal morbidity to a minimum.

The difficulties of pre-operative diagnosis are illustrated in the report by Abitbol (1958) of a maternal death after rupture of the common bile-duct at the 34th week of pregnancy, and by Stone (1957), who described a perforation of the gall-bladder in the eighth month of pregnancy. In only the latter report was the diagnosis made pre-operatively.

The infrequent occurrence of this grave surgical emergency in pregnancy makes pre-operative diagnosis essential and prompt surgical intervention necessary so that immediate cholecystectomy may be performed and maternal and foetal mortality prevented.

We would like to thank Mr. T. B. FitzGerald for permission to publish this case.

G. A. MOREwOOD, M.B., CH.B., D.R.C.O.G., Senior House Officer, St. Mary's Hospital, Manchester.

R. Pilkington, M.B., B.S., M.R.C.o.G., Registrar, St. Mary's Hospital, Manchester.

\section{REFERENCES}

Abitbol, M. M. (1958). Amer. 7. Obstet. Gynec., 76, 599. Bailey, H., and Love, McN. (1959). A Short Practice of Surgery, 11 th ed., p. 441. Lewis, London. Becker, W. F. (1957). Surg. Gynec. Obstet., 105, 636 Becker, W. F. (1957). Surg. Gynec. Obstet., 105,

Fletcher, A. G., jun., and Ravdin, I. S. (1951). Amer. Y. Surg., 81, 178. Hallendorf, L. C., Dockerty, M. B., and Waugh, J. M. (1948). Surg. Clin. N. Amer., 28, 979.

Morse, L., Krynski, B., and Wright, A. R. (1957). Amer. F. Surg., 94, 772. Reid, D. E. (1962). Textbook of Obstetrics, p. 881. Saunders, Phila-

Stone, W. W. (1937). F. Amer. med. Ass., 109, 1903. 